\title{
PRODUTIVIDADE DE MINICEPAS DE CEDRO-AUSTRALIANO EM FUNÇÃO DO TEOR INICIAL DE NUTRIENTES
}

\author{
Juliana Sobreira de Souza ${ }^{1 *}$, Deborah Guerra Barroso ${ }^{1}$, Mírian Peixoto Soares da Silva ${ }^{1}$, \\ Daniele de Alvarenga Ferreira ${ }^{2}$ \\ ${ }^{1 *}$ Universidade Estadual do Norte Fluminense Darcy Ribeiro, Campos dos Goytacazes, Rio de Janeiro, Brasil - \\ julianauenf@gmail.com; deborah@uenf.br; mirianpsoares@gmail.com \\ ${ }^{2}$ Viveiro Mundo Verde, Bom Jesus do Itabapoana, Rio de Janeiro, Brasil - ferreira.da @ gmail.com
}

Recebido para publicação: 16/05/2014 - Aceito para publicação: 24/04/2015

\begin{abstract}
Resumo
O objetivo do presente estudo foi avaliar a produtividade de minicepas de cedro-australiano em função do teor inicial de nutrientes em dois sistemas de minijardim multiclonal, conduzidos em canaletão e tubetes. Foi determinada a produtividade de miniestacas em 186 minicepas em cada sistema de manejo e os teores de nutrientes nas brotações emitidas por 20 minicepas selecionadas ao acaso em cada sistema. Foram realizadas cinco coletas de brotações em intervalos médios de 32 dias no sistema canaletão, enquanto no sistema tubete foram realizadas três coletas de brotações em intervalos médios de 31 dias. O número de miniestacas produzidas por minicepa foi correlacionado com o teor inicial de nutrientes da parte apical das mudas. A produtividade de minicepas de cedroaustraliano manejadas em sistema canaletão e em tubetes está relacionada à nutrição mineral. Assim, níveis elevados de nutrientes nas minicepas favorecem o ganho em produtividade. Dessa forma, a reposição dos nutrientes conforme a exportação descrita favorecerá o aumento da produtividade das minicepas nos dois sistemas de produção.

Palavras-chave: Propagação vegetativa; Toona ciliata; minijardim multiclonal; nutrição mineral.
\end{abstract}

\begin{abstract}
Productivity of cedar Australian ministumps in function of the initial nutrient. The aim of this research was to evaluate the productivity of Australian cedar ministumps in function of the initial content of nutrients in two systems of multiclonal minigarden; the experiment was conducted in tray and tubes. We determined the yield of minicuttings in 186 ministumps in each management system and the nutrient contents in shoots issued for 20 ministumps randomly selected in each system. We made a total of five collections of shoots in intervals of 32 days in the tray system, while in the cartridges system we made three collections of shoots in intervals of 31 days. The number of minicuttings produced by mini-stump was correlated with the initial content of nutrients in the apical part of seedlings. The productivity of australian cedar ministumps managed under tray and tubes is related to mineral nutrition. Thus, high levels of nutrients work in favor of ministumps gain in productivity. As result, the recovery of export nutrients, as described, work in favor of increased productivity of ministumps in both systems.

Keywords: Vegetative propagation; Toona ciliata; multiclonal minigarden; mineral nutriton.
\end{abstract}

\section{INTRODUÇÃO}

Dentre as espécies introduzidas no Brasil e utilizadas na produção comercial de madeira, vem se destacando a Toona ciliata M. Roemer var. australis, conhecida popularmente como cedro-australiano, que apresenta algumas características de importância econômica, como ciclo relativamente curto, boa produtividade de madeira e alto valor no mercado interno e externo (PINHEIRO et al., 2006). Sua madeira apresenta semelhanças com os cedros nativos do Brasil (Cedrela odorata L. e Cedrela fissilis Vell.) (PINHEIRO et al., 2003).

No Brasil, essa espécie encontrou condições favoráveis para sua adaptação, aliada à resistência a Hypsipyla grandella, uma broca que ataca o broto terminal do cedro nativo (LIAO et al., 2007; FERREIRA et al., 2012; PEREZ et al., 2010).

A propagação comercial do cedro realizada via seminífera (PINHEIRO et al., 2003; SCOCCHI et al., 2006) resulta em produção irregular e população heterogênea, devido à variabilidade do material genético. 
Nesse sentido, a propagação vegetativa torna-se uma alternativa para se contornarem os problemas de sazonalidade, viabilidade e heterogeneidade do material seminífero (SCOCCHI et al., 2006), permitindo rápida seleção e multiplicação de indivíduos com características desejáveis, garantindo a produção em menor espaço de tempo.

A propagação vegetativa de cedro australiano por miniestaquia mostra-se viável em inúmeros trabalhos (SOUZA et al., 2009; SILVA et al., 2012; FERREIRA et al., 2012). Essa técnica, associada a processos de seleção de materiais, tem proporcionado considerável ganho em produtividade, uniformidade e aumento no percentual de enraizamento das estacas, quando se controlam os fatores ambiental, fitopatológico e nutricional do jardim clonal (TITON et al., 2003).

O estado nutricional da matriz fornecedora de propágulos é fator determinante do sucesso na propagação vegetativa. Tal estado vai determinar a quantidade de carboidratos e auxinas, entre outros compostos metabólicos, fundamentais à indução e crescimento das raízes (CUNHA et al., 2009), à produtividade das minicepas (CUNHA et al., 2008) e à qualidade das mudas, uma vez que os macro e micronutrientes estão envolvidos nos processos vitais da planta (PAULA et al., 2000). De acordo com Souza Júnior et al. (2008), um manejo adequado das minicepas aliado a uma nutrição mineral específica influencia diretamente a produção de miniestacas. Vale destacar que tanto as doses quanto a fonte dos nutrientes podem alterar a produtividade das minicepas (HIGASHI et al., 2000; ROSA et al., 2009).

O manejo de minicepas para produção de miniestacas resulta em grande remoção de nutrientes, sendo necessária a reposição, adequadamente distribuída ao longo do tempo. Entretanto, não há informações sobre a nutrição das minicepas e a produção de miniestacas de cedro-australiano. Assim, pesquisas referentes à nutrição mineral e à produtividade de minicepas do cedro-australiano (Toona ciliata M. Roemer var. australis) são importantes para viabilizar a fertilização adequada para a produção em escala comercial dessa espécie por miniestaquia.

Diante do exposto, o objetivo do presente estudo foi avaliar a produtividade de minicepas de cedro-australiano em função do teor inicial de nutrientes em dois sistemas de minijardim multiclonal, conduzidos em canaletão e tubetes.

\section{MATERIAL E MÉTODOS}

O experimento foi conduzido na Unidade de Apoio à Pesquisa (UAP) da Universidade Estadual do Norte Fluminense (UENF), no município de Campos dos Goytacazes, RJ (21¹9'23" latitude Sul, 41 19 '41" longitude Oeste), na região Norte Fluminense. O experimento teve início em fevereiro de 2009 e encerramento em novembro de 2009. De acordo com a classificação de Köppen, o clima da região é do tipo Aw, tropical quente e úmido, com período seco no inverno e chuvoso no verão.

Foram adquiridas sementes de Toona ciliata M. Roemer var. australis provenientes de Área de Produção de Sementes (APS) localizada em Venda Nova do Imigrante, ES, da firma Caiçara Comércio de Sementes Ltda., com sede em Brejo Alegre, SP. As sementes foram utilizadas para a produção de mudas em casa de vegetação com cobertura plástica de polipropileno de $150 \mu \mathrm{m}$ e sombrite $30 \%$.

A semeadura foi efetuada em 1000 tubetes plásticos, com $180 \mathrm{~cm}^{3}$ de volume, contendo mistura composta por substrato comercial (Plantmax ${ }^{\circledR}$ florestal), fibra de coco e torta de filtro, na proporção de 2:1:1, respectivamente, sendo colocadas três sementes por recipiente. Foram adicionados ao substrato 2,2 kg.m $\mathrm{m}^{-3}$ de ureia revestida, conforme a dose aplicada para citros (AZEVEDO et al., 2009) e 1,5 kg. $\mathrm{m}^{-3} \mathrm{de}$ superfosfato simples. A semeadura foi realizada em 11 de fevereiro de 2009.

Foram selecionadas 372 mudas produzidas nos tubetes para a implantação dos minijardins multiclonais (canaletão e tubete), sendo a metade repicada para o canaletão dois meses após a semeadura.

As 186 minicepas do sistema tubete utilizadas no experimento ficaram dispostas em bandejas, arranjadas aleatoriamente sobre as bancadas, mantidas suspensas a um metro da superfície do solo, em casa de vegetação, em uma área total de $1,92 \mathrm{~m}^{2}$. Cada bandeja apresentou capacidade para armazenar 54 minicepas, sendo mantidas apenas 27 minicepas por bandeja, enquanto que as 186 minicepas do sistema canaletão ficaram dispostas em dois canaletões, em uma área total de $5,40 \mathrm{~m}^{2}$. O espaçamento entre as minicepas no canaletão foi de $0,15 \times 0,15 \mathrm{~m}$.

O minijardim multiclonal em tubetes e em canaletão foi instalado em casa de vegetação. Aos 96 dias após a semeadura (DAS), as mudas de ambos os sistemas de produção foram submetidas à poda apical, a $8 \mathrm{~cm}$ a partir do colo das mudas, para obtenção das minicepas, responsáveis pela emissão das brotações.

Foi coletada a parte apical (acima de $8 \mathrm{~cm}$ de altura do colo das mudas) de 20 mudas de cada sistema de manejo, para análise nutricional, a fim de obter o teor inicial de nutrientes das minicepas. Após a poda apical, as minicepas emitiram brotações, sendo coletadas 20 amostras (todas as brotações acima de 
$5 \mathrm{~cm}$ presentes na minicepa) de cada sistema de manejo, para avaliação nutricional e a contagem do número de miniestacas produzidas por minicepa que apresentavam altura acima de $5 \mathrm{~cm}$, para preparo das miniestacas. A seleção das 20 minicepas de cada sistema de manejo foi realizada aleatoriamente, na primeira coleta da parte apical das mudas.

Após cada coleta, as 20 amostras de cada sistema foram acondicionadas em sacos de papel e colocadas em estufa para secagem a $70^{\circ} \mathrm{C}$, durante $72 \mathrm{~h}$, sendo depois trituradas em moinho tipo Willey, usando peneira de 20 mesh. Posteriormente, o material triturado foi submetido a análises químicas, para determinação dos teores de nitrogênio em extrato sulfúrico; fósforo, potássio, cálcio, magnésio, enxofre, zinco, cobre, ferro e manganês em extrato nitroperclórico; e boro em extrato de ácido clorídrico, de acordo com metodologia descrita por Malavolta et al. (1997).

A periodicidade (número e intervalo) entre coletas foram determinados em função do crescimento das brotações. Foram realizadas seis coletas (incluindo a coleta da parte apical das mudas no tempo 0) no sistema canaletão, com a periodicidade de $0,50,86,115,149$ e 177 dias após a poda apical (DAPA), enquanto que no sistema de tubetes (incluindo a coleta da parte apical no tempo 0) foram realizadas quatro coletas com a periodicidade de $0,115,149$ e 177 DAPA. O tempo zero se refere ao momento da poda apical, na qual as mudas receberam a poda do ápice (acima de $8 \mathrm{~cm}$ do colo das mudas) que, em intervalos variáveis, de acordo com o sistema de manejo, emitiu novas brotações. A poda apical ocorreu no dia 18 de maio de 2009.

Após a primeira coleta de brotações, as minicepas dos tubetes só emitiram brotações mediante a aplicação semanal de 6,5 g.L $\mathrm{L}^{-1}$ de $\left(\mathrm{NH}_{4}\right)_{2} \mathrm{SO}_{4}$ a partir dos 175 dias após a semeadura (DAS) até aos 273 DAS.

O número total de miniestacas obtido nos dois sistemas (canaletão e tubetes) foi utilizado nas análises estatísticas, visando estabelecer correlações entre a produtividade das minicepas e teores iniciais dos nutrientes nas minicepas.

Os dados foram analisados por amostragem simples ao acaso, considerando uma população infinita de miniestacas, em dois sistemas de minijardim multiclonal (tubete e canaletão). Foram realizadas correlações de Pearson entre os teores iniciais de macro e micronutrientes nas minicepas e o número de miniestacas produzidas ao nível de significância de 5\% de probabilidade. As análises foram realizadas utilizando o SANEST 1985.

\section{RESULTADOS E DISCUSSÃO}

Os valores médios das concentrações de nitrogênio foram superiores no minijardim multiclonal em canaletão apenas no tempo zero (poda apical das mudas) e aos 115 dias após a poda apical (DAPA), em relação aos valores encontrados no minijardim multiclonal em tubetes (Tabela 1; Tabela 2). Foi observada correlação positiva entre o teor de nitrogênio e a produtividade de miniestacas nos minijardins multiclonais em canaletão e em tubetes (Tabela 3). Resultados semelhantes aos encontrados neste estudo foram observados por Cunha et al. (2008), em que os autores observaram correlação positiva entre o teor de nitrogênio e o número de miniestacas para um clone de eucalipto, no minijardim clonal em leito de areia, indicando que, para aumentar a produtividade de miniestacas, seria necessário aumentar a dose de nitrogênio para o referido clone, uma vez que o nitrogênio é o nutriente responsável pelo crescimento vegetativo (TAIZ; ZEIGER, 2004). Já no minijardim clonal em tubetes, esses autores verificaram correlação negativa significativa para dois clones, verificando-se a necessidade de diminuir as doses de nitrogênio para esses clones, visando aumentar a produtividade de miniestacas. Rosa et al. (2009) utilizando diferentes doses de nitrogênio $\left(0,2 ; 0,4\right.$ e 0,6 g.L $\mathrm{L}^{-1}$; fonte utilizada: $\left.\mathrm{NH}_{4} \mathrm{NO}_{3}\right)$ na fertirrigação de minicepas de Eucalyptus dunnii em minijardim clonal em tubetes, observaram que a forma nitrogenada influenciou positivamente a produtividade das minicepas, mas a forma amoniacal foi a que apresentou resultados superiores. Ainda, verificou-se que as doses de nitrogênio ministradas às minicepas apresentaram relação direta com a produtividade de brotações por essas minicepas. Resultados semelhantes foram obtidos por Rosa et al. (2011) ao trabalharem com erva-mate em minijardim clonal em tubetes. Os autores observaram uma produção crescente de miniestacas à medida que se aumentava a quantidade de nitrogênio. Carvalho Neto et al. (2011) avaliaram a influência de diferentes doses nitrogênio (50, 100, 200 e $400 \mathrm{mg} . \mathrm{L}^{-1}$ ), na forma de ureia, na produção de miniestacas de Eucalyptus urophylla em solução nutritiva e observaram um declínio no número de miniestacas com o aumento das doses desse nutriente.

Os teores de fósforo nas miniestacas diferiram entre os dois sistemas, exceto aos 115 dias após a poda apical (DAPA), em que os teores de fósforo nas miniestacas do canaletão foram significativamente semelhantes aos dos tubetes (Tabela 1). Foi observada correlação positiva entre a concentração de fósforo e o número de miniestacas (Tabela 3). Assim como observado para o nitrogênio, se faz necessário o monitoramento da adubação fosfatada para aumentar a produtividade de miniestacas. Entretanto, Cunha et

FLORESTA, Curitiba, PR, v. 45, n. 3, p. 617 - 624, jul. / set. 2015.

Souza, J. S. de

ISSN eletrônico 1982-4688 / ISSN impresso 0015-3826

DOI: $10.5380 /$ rf.v45i3.36529 
al. (2008) observaram correlação negativa para um clone de eucalipto no minijardim multiclonal em leito de areia, afirmando a necessidade de diminuir a dose de fósforo para o aumento da produtividade de miniestacas. Segundo esses autores, para o minijardim clonal em tubetes não foi observada correlação significativa para todos os clones estudados, uma vez que, para todos os clones, as médias de concentração dos nutrientes estavam dentro de níveis adequados, bem como a frequência de casos do nutriente nas miniestacas. Carvalho Neto et al. (2011) utilizaram diferentes doses de fósforo (7,5, 15, 30 e $\left.60 \mathrm{mg} . \mathrm{L}^{-1}\right) \mathrm{na}$ forma de ácido fosfórico, a fim de avaliar a produção de miniestacas de Eucalyptus urophylla em solução nutritiva e constataram que o maior número de miniestacas foi obtido na dose de 7,5 mg. $\mathrm{L}^{-1}$ de fósforo.

Tabela 1. Médias das concentrações de macronutrientes de miniestacas de cedro-australiano, produzidas nos sistemas de minijardins de canaletão (C) e tubetes (T).

Table 1. Mean concentrations of macronutrients in Australian cedar minicutting, produced in suspended seedbed $(\mathrm{C})$ and tubes $(\mathrm{T})$ minigarden systems.

\begin{tabular}{|c|c|c|c|c|c|c|c|c|c|c|c|c|}
\hline \multirow{2}{*}{$\begin{array}{l}\text { Coleta } \\
\text { DAPA }^{1}\end{array}$} & \multicolumn{2}{|c|}{ Nitrogênio } & \multicolumn{2}{|c|}{ Fósforo } & \multicolumn{2}{|c|}{ Potássio } & \multicolumn{2}{|c|}{ Enxofre } & \multicolumn{2}{|c|}{ Cálcio } & \multicolumn{2}{|c|}{ Magnésio } \\
\hline & $\mathrm{C}$ & $T$ & $\mathrm{C}$ & $T$ & $\mathrm{C}$ & $\mathbf{T}$ & $\mathrm{C}$ & $T$ & $\mathrm{C}$ & $T$ & $\mathrm{C}$ & $\mathbf{T}$ \\
\hline $0^{2}$ & $35,8 \pm 1,3$ & $19,8 \pm 2,1$ & $5,8 \pm 0,3$ & $3,3 \pm 0,2$ & $25,5 \pm 1,2$ & $17,4 \pm 1,5$ & $2,3 \pm 0,2$ & $2,7 \pm 0,7$ & $13,3 \pm 0,6$ & $7,9 \pm 0,5$ & $4,1 \pm 0,3$ & $3,2 \pm 0,2$ \\
\hline 50 & $32,0 \pm 1,2$ & - & $5,4 \pm 0,3$ & - & $25,2 \pm 1,9$ & - & $2,6 \pm 0,3$ & - & $13,6 \pm 0,9$ & - & $4,0 \pm 0,3$ & - \\
\hline 86 & $31,1 \pm 1,2$ & - & $4,7 \pm 0,7$ & - & $33,9 \pm 1,3$ & - & $1,7 \pm 0,4$ & - & $13,2 \pm 0,9$ & - & $3,4 \pm 0,3$ & - \\
\hline 115 & $32,1 \pm 1,6$ & $25,4 \pm 3,6$ & $5,6 \pm 1,8$ & $4,2 \pm 1,1$ & $35,0 \pm 2,6$ & $16,2 \pm 1,8$ & $1,5 \pm 0,1$ & $1,7 \pm 0,6$ & $14,4 \pm 1,4$ & $6,8 \pm 0,9$ & $3,4 \pm 0,2$ & $2,1 \pm 0,3$ \\
\hline 149 & $30,4 \pm 1,2$ & $32,3 \pm 3,2$ & $4,4 \pm 0,2$ & $3,7 \pm 0,4$ & $31,3 \pm 1,5$ & $15,4 \pm 2,2$ & $1,6 \pm 0,1$ & $1,6 \pm 0,1$ & $14,7 \pm 1,4$ & $4,8 \pm 0,7$ & $3,3 \pm 0,3$ & $2,8 \pm 0,3$ \\
\hline 177 & $30,6+1,1$ & $31,7+1,3$ & $4,5 \pm 0,3$ & $3,8 \pm 0,4$ & $26,6 \pm 1,5$ & $9,5 \pm 1,5$ & $2,0 \pm 0,1$ & $2,3 \pm 0,2$ & $16,3 \pm 0,9$ & $5,0 \pm 0,8$ & $3,5 \pm 0,3$ & $3,2 \pm 0,4$ \\
\hline
\end{tabular}

Tabela 2. Médias das concentrações de micronutrientes de miniestacas de cedro-australiano, produzidas nos sistemas de minijardins de canaletão (C) e tubetes $(\mathrm{T})$.

Table 2. Mean concentrations of micronutrients in Australian cedar minicutting, produced in suspended seedbed (C) and tubes (T) minigarden systems.

\begin{tabular}{|c|c|c|c|c|c|c|c|c|c|c|}
\hline \multirow{2}{*}{$\begin{array}{c}\text { Coleta } \\
\text { DAPA }^{1}\end{array}$} & \multicolumn{2}{|c|}{ Boro } & \multicolumn{2}{|c|}{ Cobre } & \multicolumn{2}{|c|}{$\begin{array}{l}\text { Ferro } \\
\left(\mathrm{mg}^{\prime} \mathrm{kg}^{-1}\right)\end{array}$} & \multicolumn{2}{|c|}{ Manganês } & \multicolumn{2}{|c|}{ Zinco } \\
\hline & $\mathbf{C}$ & $\mathbf{T}$ & $\mathrm{C}$ & $\mathbf{T}$ & $\mathrm{C}$ & $\mathbf{T}$ & $\mathbf{C}$ & $\mathbf{T}$ & $\mathbf{C}$ & $\mathbf{T}$ \\
\hline $0^{2}$ & $43,4 \pm 4,1$ & $37,6 \pm 4,4$ & $7,2 \pm 0,4$ & $3,5 \pm 0,6$ & $91,8 \pm 3,8$ & $68,0 \pm 4,0$ & $191,1 \pm 29,5$ & $73,7 \pm 8,9$ & $49,9 \pm 2,7$ & $36,7 \pm 4,9$ \\
\hline 50 & $35,3 \pm 3,2$ & - & $7,5 \pm 0,6$ & - & $112,5 \pm 12,0$ & - & $214,3 \pm 26,2$ & - & $53,6 \pm 3,2$ & - \\
\hline 86 & $41,0 \pm 2,5$ & - & $6,3 \pm 0,5$ & - & $131,0 \pm 17,2$ & - & $222,1 \pm 31,4$ & - & $64,6 \pm 5,6$ & - \\
\hline 115 & $37,5 \pm 3,1$ & $45,4 \pm 3,7$ & $6,9 \pm 0,7$ & $2,7 \pm 0,6$ & $128,2 \pm 33,2$ & $60,8 \pm 4,8$ & $232,9 \pm 34,0$ & $60,7 \pm 9,2$ & $71,1 \pm 8,8$ & $40,9 \pm 2,6$ \\
\hline 149 & $31,1+2,9$ & $26,5 \pm 3,3$ & $6,6 \pm 0,7$ & $7,5 \pm 4,7$ & $84,3 \pm 23,4$ & $47,0 \pm 12,3$ & $197,1 \pm 27,7$ & $73,0 \pm 10,0$ & $66,6 \pm 8,1$ & $42,5 \pm 4,8$ \\
\hline 177 & $38,9 \pm 4,2$ & $29,5 \pm 3,3$ & $6,6 \pm 0,5$ & $5,2 \pm 0,8$ & $145,3 \pm 25,3$ & $67,7 \pm 6,8$ & $239,0 \pm 40,9$ & $93,0 \pm 13,6$ & $75,9 \pm 8,7$ & $47,2 \pm 5,6$ \\
\hline
\end{tabular}

${ }^{1}$ DAPA: dias após a poda apical; ${ }^{2} 0$ : se refere ao momento da poda apical, ou seja, refere-se a poda do ápice das mudas; (-) aos 50 e 86 DAPA, as minicepas presentes nos tubetes não emitiram brotações.

Tabela 3. Coeficiente de correlação de Pearson entre concentrações de macro e micronutrientes iniciais e a produtividade de minicepas de cedro-australiano, produzidas em canaletão e tubetes.

Table 3. Pearson correlation coefficient between initial macro and micronutrients concentrations and the productivity of Australian cedar ministumps produced in suspended seedbed and tubes.

\begin{tabular}{lc}
\hline Nutrientes & Correlação \\
\hline $\mathrm{N}$ & $0,78^{*}$ \\
$\mathrm{P}$ & $0,71^{*}$ \\
$\mathrm{~K}$ & $0,73^{*}$ \\
$\mathrm{~S}$ & $-0,29^{\text {ns }}$ \\
$\mathrm{Ca}$ & $0,72^{*}$ \\
$\mathrm{Mg}$ & $0,59^{*}$ \\
$\mathrm{~B}$ & $0,19^{\mathrm{ns}}$ \\
$\mathrm{Cu}$ & $0,72^{*}$ \\
$\mathrm{Fe}$ & $0,78^{*}$ \\
$\mathrm{Mn}$ & $0,76^{*}$ \\
$\mathrm{Zn}$ & $0,50^{*}$ \\
\hline$*$ : significativo ao nível de 5\% de probabilidade de erros; ns: não significativo.
\end{tabular}


As concentrações médias de potássio (Tabela 1) nas miniestacas diferiram entre os sistemas de produção (canaletão e tubete). Foram observadas correlações positivas entre o teor de potássio e o número de miniestacas (Tabela 3). Os resultados observados estão de acordo com Paula et al. (2000) e Cunha et al. (2008), que obtiveram efeitos positivos do potássio na produtividade de estacas de eucalipto no minijardim clonal em tubete e em leito de areia para dois clones de eucalipto, respectivamente. Segundo Cunha et al. (2008), apesar das médias de as concentrações de potássio para esses dois clones se enquadrarem dentro de níveis adequados, esse fato indica que os níveis de adequação propostos na literatura não se aplicam a todos os materiais genéticos, sendo os teores ideais diferentes entre os clones e/ou material genético. Dessa forma, é necessário aumentar a dose de potássio visando maior número de miniestacas. Entretanto, esses autores verificaram, no minijardim clonal em tubetes, que os resultados encontrados foram contrários aos anteriormente citados, observando-se efeitos negativos significativos entre os teores de potássio e o número de miniestacas para um clone, de modo que uma diminuição na dose de potássio é necessária, visando aumento do número de miniestacas. Carvalho Neto et al. (2011) utilizaram doses crescentes de potássio (50, 100,200 e $400 \mathrm{mg} . \mathrm{L}^{-1}$ ) na forma de cloreto de potássio na solução nutritiva, para verificar a produção de miniestacas de Eucalyptus urophylla. Os autores observaram que a dose de $50 \mathrm{mg}^{\mathrm{L}} \mathrm{L}^{-1}$ de potássio contribuiu para a obtenção do maior do número de miniestacas.

Com relação ao enxofre, as concentrações médias encontradas nas miniestacas não diferiram entre os sistemas de produção (canaletão e tubete), com exceção aos 177 dias após a poda apical (DAPA), em que os teores de enxofre nas miniestacas do canaletão foram inferiores quando comparadas com os teores observados nas miniestacas dos tubetes (Tabela 1). Nos minijardins multiclonais, não houve correlação significativa entre os teores de enxofre e o aumento no número de miniestacas (Tabela 3). Resultado semelhante foi observado por Cunha et al. (2008), ao trabalharem com miniestacas de eucalipto em minijardim clonal em tubetes. Ao contrário do encontrado nos tubetes, esses autores observaram que o enxofre influenciou negativa e significativamente o número de miniestacas no minijardim clonal em leito de areia, em quatro clones de eucalipto, indicando que uma diminuição nos teores desse elemento aumentaria a produtividade de miniestacas.

As médias de concentração de cálcio nas miniestacas foram superiores no sistema canaletão quando comparadas com o sistema em tubetes (Tabela 1). O cálcio influenciou positivamente o número de miniestacas no minijardim multiclonal em canaletão e em tubete (Tabela 3). Entretanto, Cunha et al. (2008) observaram resultados divergentes ao encontrado neste estudo. Esses autores notaram que o cálcio influenciou negativamente o número de miniestacas de quatro clones no minijardim clonal em leito de areia, e de dois clones no minijardim clonal em tubetes. Assim, para os clones citados, menores doses de cálcio, em relação ao que vem sendo empregado, são indicadas para aumentar a produtividade de miniestacas por minicepa. De acordo com os resultados obtidos neste estudo, pode-se dizer que possivelmente a produção de miniestacas é dependente das concentrações de cálcio.

Os teores de magnésio encontrados nas miniestacas foram inferiores no minijardim multiclonal em tubete no tempo zero e aos 115 DAPA em comparação ao sistema em canaletão (Tabela 1). Foi observado efeito positivo do magnésio na produção de miniestacas nos dois minijardins multiclonais em canaletão e em tubete (Tabela 3). Resultados semelhantes foram observados por Cunha et al. (2008), que observaram efeito positivo significativo para um clone no minijardim clonal em tubete. Esses autores observaram efeito negativo significativo para três clones no minijardim clonal em leito de areia.

De modo similar ao verificado para todos os macronutrientes, exceto para o enxofre, o número de miniestacas é dependente da concentração de magnésio nas minicepas (fonte de propágulos). Assim, níveis elevados desses nutrientes nas minicepas possivelmente favorecem um ganho em produtividade, até um nível crítico não pesquisado neste trabalho.

Com relação ao boro, as concentrações médias encontradas nas miniestacas não diferiram entre os minijardins multiclonais (canaletão e tubete), exceto aos 115 DAPA, em que os teores de boro nas miniestacas conduzidas em canaletão foram inferiores quando comparadas com os teores observados nas miniestacas do minijardim em tubetes, e aos 177 DAPA, em que os teores de boro nas miniestacas conduzidas em canaletão foram superiores em comparação com o minijardim em tubetes (Tabela 2). Nos minijardins multiclonais não houve correlação significativa entre os teores de boro e o aumento no número de miniestacas (Tabela 3). Entretanto, Cunha et al. (2008) observaram que o boro influenciou negativa e significativamente o número de miniestacas em um clone de eucalipto no minijardim clonal em tubetes. Dessa forma, esses autores indicaram que uma diminuição da dose do nutriente aumentaria o número de miniestacas. Freitas (2013) avaliou a produtividade de minicepas de híbridos de Eucalyptus globulus em resposta a diferentes doses de boro $\left(78,157,237,356\right.$ e $\left.475 \mu \mathrm{g} . \mathrm{L}^{-1}\right)$ aplicadas em solução nutritiva em minijardim clonal de leito de areia. $\mathrm{O}$ autor verificou que apenas um clone apresentou resultado significativo para as doses aplicadas, tendo o boro proporcionado ganhos consideráveis em produtividade de brotos.

As concentrações médias de cobre nas miniestacas foram superiores no minijardim multiclonal em canaletão em comparação com minijardim multiclonal em tubetes, exceto aos 149 DAPA (Tabela 2).

FLORESTA, Curitiba, PR, v. 45, n. 3, p. 617 - 624, jul. / set. 2015.

Souza, J. S. de

ISSN eletrônico 1982-4688 / ISSN impresso 0015-3826 
O cobre influenciou positiva e significativamente o número de miniestacas nos minijardins multiclonais (Tabela 3). Assim, um aumento da dose do nutriente provavelmente aumentaria o número de miniestacas. Cunha et al. (2008) observaram correlações positivas significativas para o cobre no minijardim clonal em leito de areia, para dois clones de eucalipto, e negativas para outros dois clones. Os autores atribuíram essa diferença nos resultados aos diversos materiais genéticos utilizados, tendo em vista que, para os clones estudados, as médias de concentrações de nutrientes se enquadravam dentro de níveis considerados adequados. Nesse mesmo estudo, para o minijardim clonal em tubetes não foi observada correlação significativa para nenhum clone de eucalipto estudado. Segundo os autores, essas correlações podem ser explicadas pelo fato de todos os clones, na maioria dos casos de frequência de concentração de cobre nos brotos, estarem dentro de níveis adequados, sendo que o mesmo ocorreu para o minijardim clonal em leito de areia.

Para o ferro, as médias de concentração nas miniestacas foram superiores no minijardim multiclonal em canaletão (Tabela 2). As correlações foram positivas e significativas entre os teores de ferro e a produtividade de minicepas (Tabela 3). Assim, um aumento na dose de ferro aumentaria a produtividade das minicepas. Esse resultado difere do encontrado por Cunha et al. (2008), que observaram correlações negativas significativas entre os teores de ferro e a produtividade de minicepas para dois clones de eucalipto no minijardim clonal em leito de areia e para um clone no minijardim clonal em tubetes. Os autores indicaram que uma diminuição na dose de ferro aumentaria a produtividade das minicepas para esses clones.

De forma semelhante ao ferro, as médias de concentração de manganês nas miniestacas foram superiores no minijardim multiclonal em canaletão (Tabela 2), indicando que o manejo nesse minijardim multiclonal está sendo mais eficiente ou que as minicepas desse minijardim são mais eficientes na absorção de manganês. As correlações também foram positivas e significativas entre os teores de manganês e o número de miniestacas produzidas (Tabela 3). Os resultados positivos relacionados à produção de brotações observados podem ser explicados em função de o manganês ser um ativador da oxidase, uma enzima que ajuda a controlar o nível de auxina (MALAVOLTA et al., 1997), favorecendo uma razão auxina/citocinina baixa, promovendo a formação de brotações (ALFENAS et al., 2009). Resultados semelhantes foram observados por Cunha et al. (2008), que verificaram efeito positivo significativo do manganês para produtividade em minijardim clonal em tubetes, para um clone de eucalipto, de forma que, para aumentar a produtividade, é necessário aumentar a dose do nutriente. Entretanto, foi observado que no minijardim clonal em leito de areia houve uma correlação negativa significativa, para três clones, sendo necessária uma diminuição da dose de manganês para aumentar a produtividade das minicepas. Essa diferença de resultados pode ser atribuída a níveis muito elevados de manganês, encontrados nas brotações do minijardim clonal em leito de areia, podendo esse nutriente estar causando problemas de toxicidade nas miniestacas e, consequentemente, estar diminuindo o número de miniestacas.

Para o zinco, as médias de concentração nas miniestacas foram superiores no minijardim clonal em canaletão em comparação com minijardim multiclonal em tubetes (Tabela 2). Foi observada correlação positiva significativa entre o teor de zinco nas miniestacas e a produtividade de miniestacas nos minijardins multiclonais em canaletão e em tubete (Tabela 3). Esse resultado divergiu do encontrado por Cunha et al. (2008), que observaram que o zinco influenciou negativa e significativamente a produtividade de miniestacas de três clones no minijardim clonal em leito de areia, e de dois clones no minijardim clonal em tubetes, indicando que menores doses desse nutriente promoveriam aumento de produtividade. Entretanto, Freitas (2013) observou que as doses de zinco (19, 37, 56, 84 e $\left.112 \mu \mathrm{g} . \mathrm{L}^{-1}\right)$ aplicadas nas minicepas de híbridos de Eucalyptus globulus em minijardim clonal em leito de areia não influenciaram significativamente a produtividade das minicepas.

Assim, para todos os micronutrientes, exceto o boro, a produtividade de minicepas é dependente da concentração de zinco. Portanto, um aumento na dose desses micronutrientes possivelmente favoreceria um ganho em produtividade. foram altos.

Com base nos resultados acima, foi possível observar que os valores de correlação encontrados

\section{CONCLUSÕES}

- A produtividade de minicepas de cedro-australiano manejadas em minijardins multiclonais em canaletão e em tubetes está relacionada com a nutrição mineral.

- O número de miniestacas é dependente da concentração dos nutrientes, exceto para o enxofre e o boro. Assim, níveis elevados desses nutrientes nas brotações possivelmente favorecem um ganho em produtividade. Dessa forma, a reposição dos nutrientes (N, P, K, Ca, Mg, Cu, Fe, Mn e Zn) pode favorecer o aumento da produtividade nos dois minijardins multiclonais. 


\section{AGRADECIMENTOS}

À CAPES - Coordenação de Aperfeiçoamento de Pessoal de Nível Superior, pela bolsa de estudo; ao técnico Armando, pela ajuda na estufa; ao técnico Acácio, pela ajuda nas análises laboratoriais.

\section{REFERÊNCIAS}

ALFENAS, A. C.; ZAUZA, E. A. V.; MAFIA, R. G.; ASSIS, T. F. Clonagem e doenças do eucalipto. Viçosa: Universidade Federal de Viçosa, 2009. 500 p.

AZEVEDO, E. B.; MARINHO, C. S.; MUNIZ, R. A.; CARVALHO, A. J. C. Substratos fertilizados com ureia revestida e o crescimento e estado nutricional da muda de citros. Acta Scientiarum Agronomy, v. 31, p. $129-137,2009$.

CARVALHO NETO, J. P.; SILVA, E. B.; SANTANA, R. C.; GRAZZIOTTI, P. H. Effect of NPK fertilization on production and leaf nutrient content of eucalyptus minicuttings in nutrient solution. $\mathbf{R}$. Bras. Ci. Solo, v. 35, p. 249 - 254, 2011.

CUNHA, A. C. M. C. M.; PAIVA, H. N.; BARROS, N. F.; LEITE, H. G.; LEITE, F. P. Relação do estado nutricional de minicepas com o número de miniestacas de eucalipto. Scientia Forestalis, v. 36, p. $203-213,2008$.

Relação do estado nutricional de minicepas com o enraizamento de miniestacas de eucalipto.

Revista Brasileira Ciência do Solo, v. 33, p. 591 - 599, 2009.

FERREIRA, D. A.; BARROSO, D. G.; SILVA, M. P. S.; SOBREIRA, J.; FREITAS, T. A. S.; CARNEIRO, J. G. A. Influência da posição das miniestacas na qualidade de mudas de cedro-australiano e no seu desempenho inicial no pós-plantio. Ciência Florestal, v. 22, p. 719 - 727, 2012.

FREITAS, A. F. Produtividade de minicepas e enraizamento de miniestacas de híbridos de Eucalyptus globulus Labill. em resposta a N, B e Zn. 85 f. Dissertação (Mestrado em Ciência Florestal) - Universidade Federal de Viçosa, Viçosa, 2013.

HIGASHI, E. N.; SILVEIRA, R. L. V. A.; VALLE, C. F.; BONINE, C. A. V.; BOUCHARDET, J. A.; GONÇALVES, A. N. Efeito da aplicação de nitrogênio na concentração de nutrientes, na produção dos nutrientes, na produção e enraizamento de miniestacas de clones de Eucalyptus na condição de minijardim clonal. In: REUNIÃO BRASILEIRA DE FERTILIDADE DO SOLO E NUTRIÇẪO DE PLANTAS, 25., 2000, Santa Maria. Anais... Santa Maria: SBCS/SBM, 2000. (CD-ROM).

LIAO, S.; YANG, S.; YUAN, T.; ZHANG, C.; CHEN, H.; WU, Y.; XU, Y.; YUE, J. Limonoids from the Leaves and Stems of Toona ciliata. Journal of Natural Products, v. 70, p. 1268 - 1273, 2007.

MALAVOlTA, E.; VITTI, G. C.; OLIVEIRA, S. A. Avaliação do estado nutricional das plantas: princípio e aplicações. Piracicaba: Potafo, 1997. 319 p.

PAULA, T. A.; SILVEIRA, R. L. V. A.; HIGASHI, E. N.; GONÇALVES, A. N. Efeito do potássio sobre a produção e enraizamento de estacas de Eucalyptus. In: REUNIÃO DE FERTILIDADE DO SOLO E NUTRIÇÃO DE PLANTAS, 25, Santa Maria, 2000. Anais... Santa Maria: SBCS/SBM, 2000.

PEREZ, J.; EIGENBRODE, S.; HILJE, L.; TRIPEPI, R.; AGUILAR, M. E.; MESEN, F. Leaves from grafted Meliaceae species affect survival and performance of Hypsipyla grandella (Zeller) (Lepidoptera: Pyralidae) larvae. Journal of Pest Science, v. 83, p. 1612 - 4758, 2010.

PINHEIRO, A. L.; LANI, L. L.; COUTO, L. Cultura do cedro-australiano para produção de madeira serrada. Viçosa, MG: Universidade Federal de Viçosa, 2003. 42 p.

PINHEIRO, A. L.; LANI, J. L.; COUTO, L. Cedro-australiano: cultivo e utilização. Viçosa, MG: Universidade Federal de Viçosa, 2006. 42 p.

ROSA, L. S.; WENDLING, I.; GROSSI, F.; REISSMANN, C. B. Efeito da dose de nitrogênio e de formulações de substratos na miniestaquia de Eucalyptus dunnii Maiden. Revista Árvore, v. 33, p. 1025 $1035,2009$. 
ROSA, L. S.; GROSSI, F.; WENDLING, I. BRONDANI, G. E. Adubação nitrogenada na fertirrigação de minicepas de Ilex paraguariensis St.-Hil. In: Congreso Sudamericano de La Yerba Mate, 5. Posadas, 2011, Acta... Posadas: INYM/ INTA/INaM, 77 - 82.

SCOCCHI, A.; DIERINGER, E.; MROGINSKI, E.; MROGINSKI, L. Conservación de semillas de cedro australiano (Toona ciliata). Plant Genetic Resources Newsletter, v. 137, p. 22 - 25, 2006.

SILVA, M. P. S.; BARROSO, D. G.; SOUZA, J. S.; FERREIRA, D. A.; CARNEIRO, J. G. A. Enraizamento de miniestacas e produtividade de minicepas de cedro-australiano manejadas em canaletões e tubetes. Ciência Florestal, v. 22, p. 707 - 717, 2012.

SOUZA, J. C. A. V.; BARROSO, D. G.; CARNEIRO, J. G. A.; TEIXEIRA, S. L.; BALBINOT, E. Propagação vegetativa de cedro-australiano (Toona ciliata M. Roemer) por miniestaquia. Revista Árvore, v. 33, p. 205 - 213, 2009.

SOUZA JÚNIOR, L.; QUOIRIN, M.; WENDLING, I. Miniestaquia de Grevillea robusta A. Cunn. a partir de propágulos juvenis. Ciência Florestal, v. 18, p. 455 - 460, 2008.

TAIZ, L.; ZEIGER, E. Fisiologia vegetal. Porto Alegre: Artmed, 2004. 719 p.

TITON, M.; XAVIER, A.; REIS, G. G.; OTONI, W. C. Eficiência das minicepas e microcepas na produção de propágulos de clones de Eucalyptus grandis. Revista árvore, v. 27, p. 619 - 625, 2003. 